\title{
Blindness in leprosy: a report on evaluation and physical rehabilitation methods
}

\author{
R PREM KUMAR \\ Schieffelin Leprosy Research and Training Centre, Karigiri, 632 \\ 106, South India
}

Accepted for publication 10 May 1983

\begin{abstract}
Summary A report is presented on rehabilitation measures used in 18 blind leprosy patients with primary and secondary deformities. The nature of their physical dysfunction, assessment methods used, effect on activities of daily living, treatment techniques to improve independent function and their effectiveness and acceptability by patients are all discussed.

The whole study is in the social context of South India and the geographical environment of a rural area.
\end{abstract}

\section{Introduction}

Of all the senses vision is the prime receiver. ${ }^{\prime}$ It is the synthesizing sense enabling priorities to be established and acted on. Leprosy produces a crippling disability by inducing blindness and loss of sensation in the extremities. Statistics suggest that $5 \%$ of persons with leprosy will ultimately become blind. ${ }^{2}$ By that time most of them are aged and totally crippled from primary and secondary deformities due to loss of sensation, muscle wasting, lack of joint movement, absorption, reaction and ulceration in the extremities. Also, such patients lose confidence in their remaining senses, contact with the environment, written communication and the basic skills which they knew beforehand.

The following report is based on our 22 months' experience in rehabilitating 18 blind leprosy patients. The objective of this is to make detailed assessments to find out the existing ability and talents of the patients and to make use of these to the maximum for retraining independence in personal care and mobility.

The methods we have used are designed for those who will return to their own homes after rehabilitation, so some of the methods will not be applicable to patients living in institutions where the inmates help each other under conditions where functional independence is not such an important factor. 


\section{Assessment and training}

\section{SUPERFICIAL AND DEEP SENSITIVITY TESTS AND TRAINING}

The non-leprosy blind person compensates for the loss of vision by developing 'fine finger-tip-touch sensibility'. Most of the blind leprosy patients we dealt with lack cutaneous sense in their fingers. If they possessed sensation, functional independence could be gained easily.

Strengthening tactile sense is done by carefully judging the sensation available and improving its perceptional ability. The method used is to ask the patient to match simple pattern puzzles using the area of islands of sensation which he has. This can be up-graded to more complicated pattern puzzles. Also, handling varieties of texture boards and blocks of various sizes and shapes is useful.

Trailing the patients hand along all the beds and lockers of his ward, along the walls of the ward and toilet interior, and on objects such as switches, windows and taps, will give a mental picture of the whole ward. This encourages the patient to learn to use his tactile and proprioceptive sense.

\section{FUNCTIONAL AND SELF-CARE ASSESSMENT AND RE-TRAINING}

The way the patient manages various self-care activities will give some information as to his complete or partial dependency, slowness in performance and/or dangers in the manner of performance, etc. Self-care assessment charts should be used to avoid missing any details. Feeding, dressing, toilet management, ambulation and travelling are the basic functional activities to be assessed in details. A four-point grading such as 1 , normal; 2 , moderately slow; 3 , very slow; and 4, unable, is found easy to use.

The aim of this self-help training is to make the patient independent in those activities in which he has previously been totally dependent on other people, and to modify and improve the activities which the patient is performing in a clumsy, slow or dangerous way. Always suggest more than one way of doing things so that the patient can select.

\section{Feeding}

Teaching the patient to eat with the spoon instead of his fingers is advisable. The patient should be taught to keep the plate, mug, spoon, etc., in a certain order so that he knows where they are. Localizing these objects is done by gently tapping around the area where they are kept (Figure 1). To pick up the spoon he has to grossly grasp in the direction of the sound. To confirm whether he has grasped it, sensation of the lips is used (Figure 2). The patient holds it properly by holding the mouthpiece of the spoon in between his teeth and then he grasps it firmly in the dominant hand. Allow the patient to use the type of grasp he is accustomed to. 


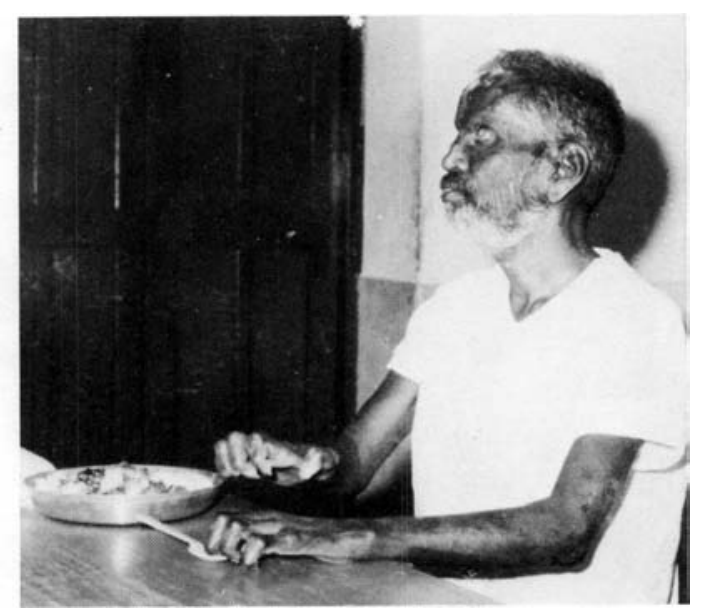

Figure 1. Identifying the position of the spoon by auditory clues.

If the patient is unable to pinch due to shortening of thumb and fingers a ' $U$ '-shaped spoon handle with padding will be found useful (Figure 3).

A mug after being located, as above, is grasped firmly with the right hand, inserting the fingers of the left hand into its handle. Before lifting it the patient has to make sure that he is holding it firmly enough by slowly lifting it a little and feeling its weight by the proprioceptive sense.

\section{Dressing}

Shirts and blouses should be a little larger than the actual size of the patient. In these, buttons and button holes are replaced with 'Velcro'. To put on these

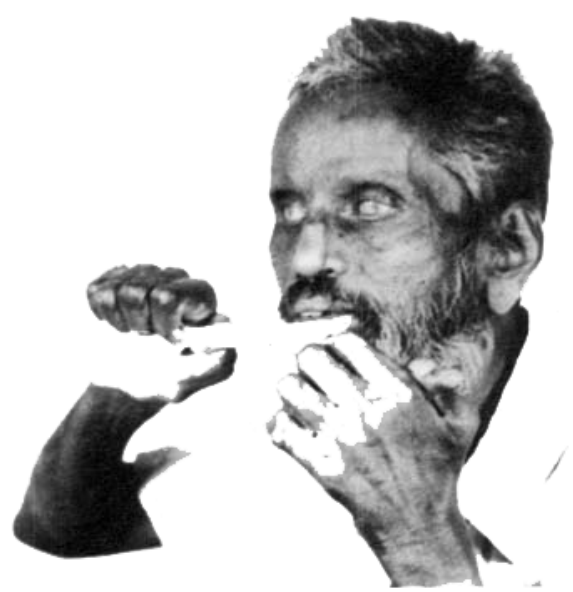

Figure 2. Identifying the part of the spoon by tactile sensation around the lips. 


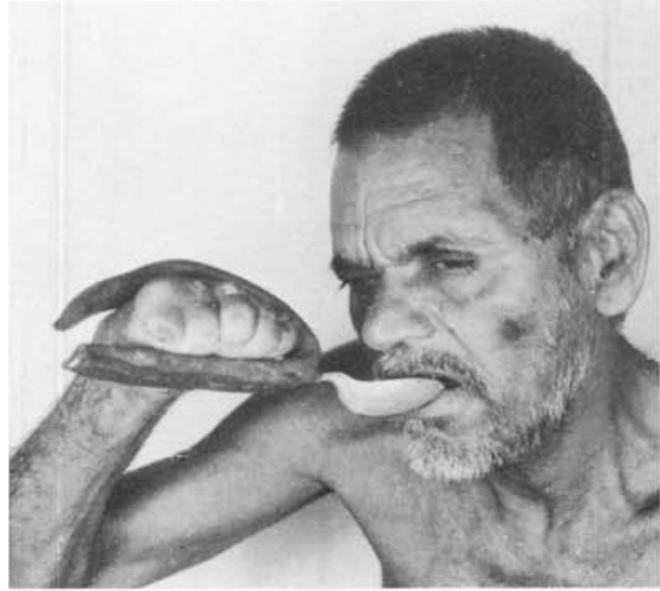

Figure 3. 'U'-shaped spoon.

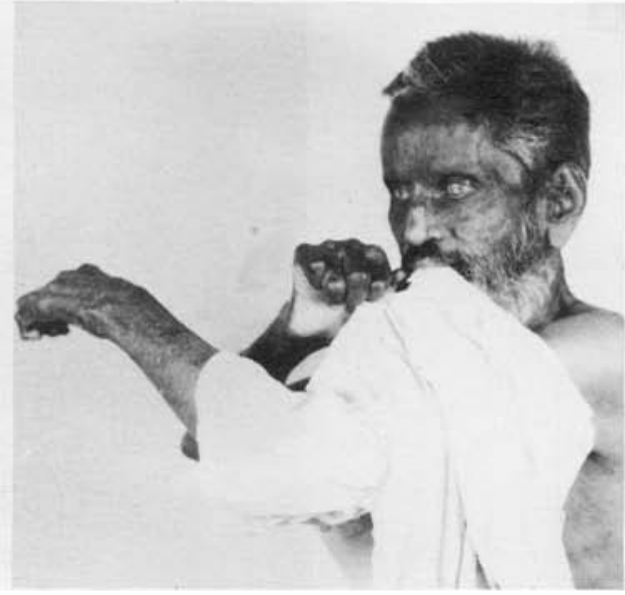

Figure 4. Identifying the centre of the collar.

garments the patient feels the centre of the collar with his lips and clenches it in between his teeth, then puts his hands into the sleeves (Figure 4). Fastening is done by grasping the edges of the shirt and with the lips identifying the texture of the 'Velcro' attached on each side. Pulling the ends of the garment apart will unfasten it and the patient can find his own way of removing it.

\section{Toilet}

In their home environment most patients defaecate in the open fields in a squatting posture. The common problem all of them expressed was difficulty in walking on the ploughed, uneven ground to reach the habitual site to defaecate. This was solved by teaching them to use a cane as a guide over uneven ground. If they still have difficulty, an additional walking stick is given to stabilize them, holding the stick in the non-dominant hand, and the cane in the dominant hand. Some patients with squatting difficulties have been given a locally produced, lightweight commode which may be kept behind a bush and carried to the habitual site when its use is required.

\section{Written communication}

For literate patients, their abilities in written communication before becoming blind should be noted and maintained. We never tried braille or touch typing because of the anaesthesia of the fingers, and also because of the late onset of the blindness but we have had some success in the use of cut-out X-ray films (Figure 5(a) and (b)). 

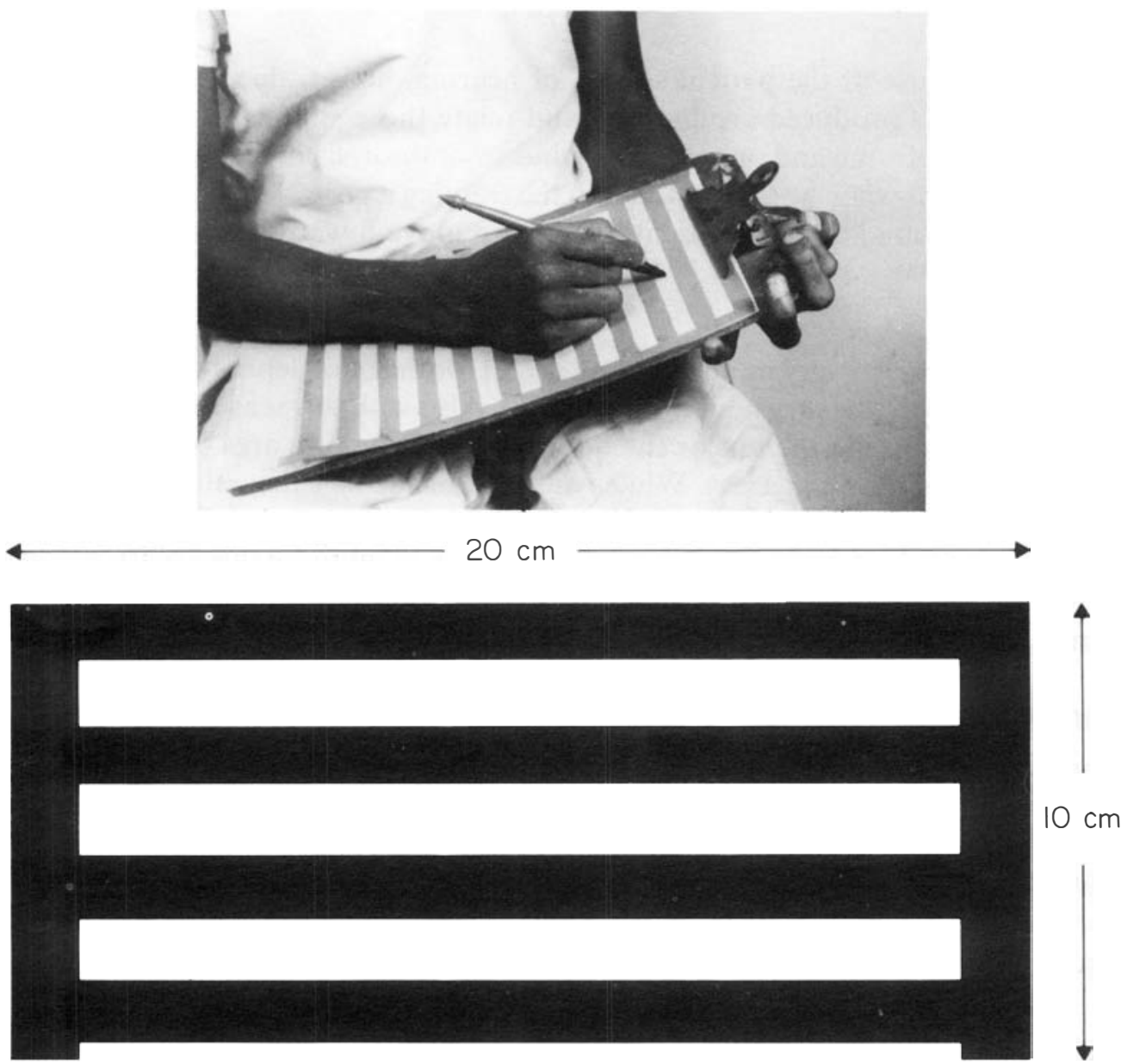

Figure 5(a). Used (discarded) X-ray film is used to aid writing for the blind patient. Using a sharp knife and a pattern, apertures are cut in the film so that it can then be placed on a sheet of paper and held in position by a clip or drawing pins. (b). Photostat copy of a piece of X-ray film with three apertures; a convenient size for the original is about $20 \times 10 \mathrm{~cm}$. The majority of patients have some degree of residual sensation in one or more fingers, enabling them to locate the edges of the film. Even with profound anaesthesia, however, the impact of the pencil against the edge of the film gives many patients (perhaps at muscle spindle level) some idea of their position on the paper.

\section{COMPENSATION THROUGH THE REMAINING SENSES}

The object of this training is to improve the ability of the remaining senses such as hearing, smell and tactile sense around the lips and the islands of sensation in the palmar surface of the hand if present, as a compensation for the loss of vision and other disabilities. Training for each of these senses is as follows: 


\section{Hearing}

To make full use of the patient's sense of hearing, he is trained to identify the various sounds produced around him and relate those sounds to their sources. For example, closing and opening of a window or door, listening to the sound an object produces when he taps it. Later in the training a person stands at a distance producing a sound and the patient is asked to move towards the sound.

\section{Smell}

The sense of smell is very important and useful for the blind leprosy patient and it enables him to detect very hot objects and fire. Also with this sense he can identify different areas inside the hut or the house (i.e. the cooking area has a different odour from the sleeping area). While walking outside he can confirm or select a particular area by identifying the smell which comes from it, like a public lavatory, fruit shop, provision shop, etc. Training to improve this ability is done by taking the patient in a wheelchair to different parts of the hospital, like the garage and the kitchen, and asking him to identify the area he is in.

\section{Light perception}

These patients often have some amount of ability to perceive light, as in leprosy only the cornea is affected and not the retina. Assessment of this is made by exposing patients to various lights, such as daylight passing through doors and windows, and light from a 40 -Watt bulb, to find out whether the patient can perceive these. Sense of direction can be taught efficiently with this perceptional ability.

\section{Mobility and orientation of the environment}

This means making the patient independent enough to move around freely and safely.

Initially, to make the patient mobile inside the ward, sighted guide techniques should be used. This technique involves asking the patient to grip above the left elbow of the guide and walk one step behind the guide. When he is taken for a walk the guide should narrate the destination and the objects at either side and also ask the patient what he has perceived using his remaining senses, such as light, olfactory and auditory perception. Sighted guide mobility training will reduce the fear of injury while walking.

\section{TYPE OF CANE}

To any blind person a cane is the instrument by which he can be really mobile. Bamboo canes are widely used in India by blind persons, but for blind leprosy 
persons aluminium canes with nylon or metal caps* are found slightly more advantageous than the bamboo cane for the following reasons: 1 Tapping with an aluminium cane can give a better auditory clue than a bamboo cane. 2 Vibrations of an aluminium cane are far superior to that of a bamboo cane. The vibrations conducted by an aluminium cane while tapping will also give additional clues as to the type of ground on which the blind person is standing. 3 Patients with a weak grip will find it easier to hold and handle aluminium canes, which are lighter in weight.

\section{CANE GUIDE TECHNIQUE}

The majority of our patients come in with bamboo canes which are used more as a support rather than as a guide. When the bamboo cane is replaced by an aluminium one the patients prefer the latter for its lightness and comfort in handling.

There is very little variation from the standard cane guide technique. The height of the cane should be up to the patient's sternum level. Indoor and smooth surface mobility is obtained by gently sliding the nylon cap of the cane on the ground, 2 feet in front and in between the legs, to make sure of the ground and of any obstruction in his path. Outside and on uneven surfaces mobility is achieved by tapping the approximate area where the leg has to be placed. This is to make sure, by using vibration and auditory sense, that the leg can be placed safely on that area.

Learning cane guide mobility takes approximately $4-6$ weeks of training. This is started with teaching the technique of smooth surface walking and progresses to uneven ground walking.

\section{HOME VISIT}

We found that at least one home visit is essential to solve a number of functional problems a patient is likely to face in his home environment. It will teach the inmates of the home, who commonly live in a joint family manner, how to assist their severely handicapped relative. In our experience, the optimum time for this visit is within 2-6 months after hospital discharge. If it is delayed beyond this period the patients, in most cases, tend to forget some of the skills learnt, the reason being that they had problems adapting such skills to suit their domestic life.

These visits showed that dressing, eating and mobility inside their homes were the activities in which most of them were totally independent or had very minimal problems, but many expressed inability or great difficulty in bathing and toilet.

\footnotetext{
* In India an aluminium cane costs approximately $£ 2$.
} 


\section{PREVENTION OF INJURIES}

The occurrence of injuries is a great problem with this group of patients. The usual practice of teaching prevention of injury by compensating for loss of sensation with sight is not possible with blind leprosy patients. We tried some of the following methods with very limited success and the study is still in progress.

The methods are: (a) Identifying the islands of sensation present to the patients and training them to perceive through them. (b) Perceptional training to use the sensation present at the dorsum of hands. (c) Using a sensory re-orientation technique. ${ }^{3}$ This technique could be of some use in teaching patients to perceive using the deep senses like joint, muscle stretch and deep pressure sense with which they can compensate for the loss of cutaneous sense.

\section{Conclusion}

Initial functional independence was achieved by training patients in mobility on even and uneven ground and orientating them to the hospital environment. Re-education in feeding, dressing and toilet activities were sufficient to lessen the burden on the family members of looking after a severely crippled relative.

The average time taken for training is about 100 hours, at the rate of two sessions per day, extended for 8-10 weeks. It was found that if there is a break in it for more than a month, for reasons like strict bed rest for ulcers or acute reactions, patients tend to forget most of the skills they have learnt before, and the training has to be started from the beginning again. If their stay is continued even after rehabilitation measures for other medical reasons, the training should be continued until their hospital discharge.

\section{Acknowledgment}

I thank Dr E P Fritschi, FRCS, for his assistance, guidance and continuous encouragement.

\section{References}

1 Report of the WFOT Bulletin-November 1978; 2: 8-9.

2 Abraham JG. Ocular Lesions (Textbook of Leprosy for Students and Para-medical Workers), Leprosy Mission, Southern Asia, New Delhi, India, 1975, p. 108.

${ }^{3}$ Parry, GBW and Salter M. 'Sensory Re-education af ter median nerve lesions'. The Hand, 1976; 8: No. 3. 